\title{
A Perspective on the Future of Distribution: Smart Grids, State of the Art, Benefits and Research Plans
}

\author{
Rosario Miceli, Salvatore Favuzza, Fabio Genduso \\ Dipartimento di Ingegneria Elettrica, Elettronica delle Telecomunicazioni, di Tecnologie Chimiche, Automatica e Modelli \\ Matematici, Università di Palermo, Palermo, Italy \\ Email:miceli@dieet.unipa.it, favuzza@dieet.unipa.it, genduso@dieet.unipa.it
}

Received September 22, 2012; revised October 28, 2012; accepted November 10, 2012

\begin{abstract}
Currently, the design and operation criteria for electrical distribution networks are fastly changing due to some factors; among these, the progressive penetration of Distributed Generation (DG) is destined to cause deep changes in the existing networks, no longer considered as passive terminations of the whole electrical system. Moreover, the increasing application of Information Communication Technologies (ICT) will allow the implementation of the so called "smart grids", determining new interesting scenarios. In the paper the problems and the potential benefits of DG, the possible new electrical distribution system models and the major research projects on smart grids are faced and reported.
\end{abstract}

Keywords: Distributed Generation; Smart Grids

\section{Introduction}

Actually, the electrical distribution systems, overall Medium Voltage (MV) ones, and their design and operation criteria are subjected to deep changes, due to different factors. Among these, the main ones concern: the energy market liberalization, the new and complex energy governance policies, the environmental pollution reduction and sustainable development, the renewable energies development, the increase of energy efficiency, the costs reduction, the growth of the penetration of the so called Distributed Generation (DG). In particular, the forthcoming presence of DG in electrical distribution systems has strongly modified the nature of such systems; these systems, in fact, having, today, a radial topology and managed in a passive way (i.e. supplying energy from electrical power plants to end-users), are destined to reach an active role by means of the implementation of the typical functions of load management, demand side management, demand response and generation curtailment $[1,2]$.

However the DG penetration determines some technical problems in electrical systems that must be faced and solved rapidly to exploit the potential benefits of DG and to really start the revision process aiming at the implementation of the so called smart grids $[3,4]$.

The smart electrical distribution grids represent the needed evolution of the actual networks by means of a deeper implementation of automation functions, and a high level of Information and Communications Technolo- gies (ICT) applications in order to increase the power quality and ancillary services, guaranteeing the security and economic/energetic efficiency in electric energy supplying [5].

After the analysis of the current scenario, characterized by the management and the problems solution determined from the above mentioned DG presence, the paper deals with the description of different possible models of smart grids (micro grids, active grids, local areas) putting in evidence the benefits and the necessary innovations which will be achieved in various fields involved in this important and fundamental evolution. Finally, to underline the importance of this issue, a brief presentation of the most important international research projects in this field are reported.

\section{Distributed Generation Possible Benefits and Problematics}

The distributed generation can introduce in electrical distribution systems some potential benefits, such as:

- Flexibility and electrical load management [6];

- Coverage of the local load peaks;

- Diversification of the energy resources supply;

- Larger possibility of exploitation of renewable energy resources in favorable locations;

- Time deferral of investments aimed at the maintainance of transmission and distribution systems, at the building of new power plants and at the reinforce- 
ment of existing power plants and electrical systems;

- Electrical energy losses reduction $[7,8]$.

On the contrary, the DG presence causes some technical problems that must be rapidly faced and solved like:

- The increase of short circuit currents;

- The increased complexity of automation and protection systems;

- The increased complexity of voltage regulation due to a modification of power flows;

- The unwanted MV systems islanding $[9,10]$.

\subsection{Increase of Short Circuit Currents}

DG connection to distribution systems by means of synchronous and asynchronous generators causes a significant increase of short circuit currents (respect to passive systems). This issue can determine the overcomeing of dimensioning and sizing limits of circuit breakers and lines. The consequence is the necessity to substitute some conductors to adapt them to the bigger thermic solicitations and some circuit breakers to adapt them to higher breaking capacity.

\subsection{Increased Complexity of Automation and Protection Systems}

DG can determine the power flow inversion in some networks branches. This depends from type of DG, power size, connection points, loads, with important consequences on protection selectivity. In fact, it is possible to have unwanted interventions over un-faulted lines, see Figure 1, due to faults in adjacent lines connected to the same bus bar (loss of selectivity). Other problem concerns possible non-functioning of opening and re-closing temporized systems to eliminate transient and semipermanent faults or to isolate faulted lines with the aim of limiting the time of out of service.

So it is necessary:

- The redefinition and re-setting of protection systems;
- The verification of protection selectivity taking in account of intensity, versus and during time of fault currents;

- The verification of time interventions of protection devices with the aim of generators stability.

\subsection{Increased Complexity of Voltage Regulation Due to a Modification of Power Flows}

As known, without DG, the voltage regulation is based on loads and passive systems features: so the voltage profile is easily determinable with regard to radial structures and stable loads (unidirectional power flows—see Figure 2).

In presence of DG, the voltage regulation is more complex, because it depends on the sites, the sizes, the dispatching and the features of DG, as shown in Figure 3. A possible solution is a voltage regulation system based on a coordinated control of under load tap changers of $\mathrm{HV} / \mathrm{MV}$ transformers and reactive power flows in distribution feeders.

\subsection{Unwanted MV Systems Islanding}

Today, in many countries, the MV systems islanding is prohibited, although it should constitute a significant potential advantage of DG. But islanding determines problems in the areas of safety, control and management. The safety aspects are related to permit repairing and

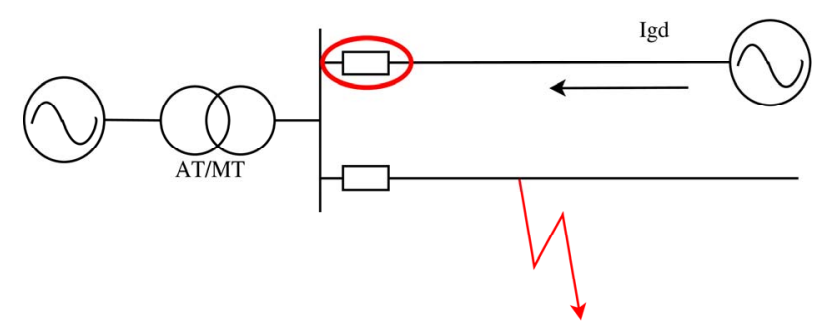

Figure 1. Loss of selectivity: unwanted intervention of a circuit breaker in an un-faulted line.

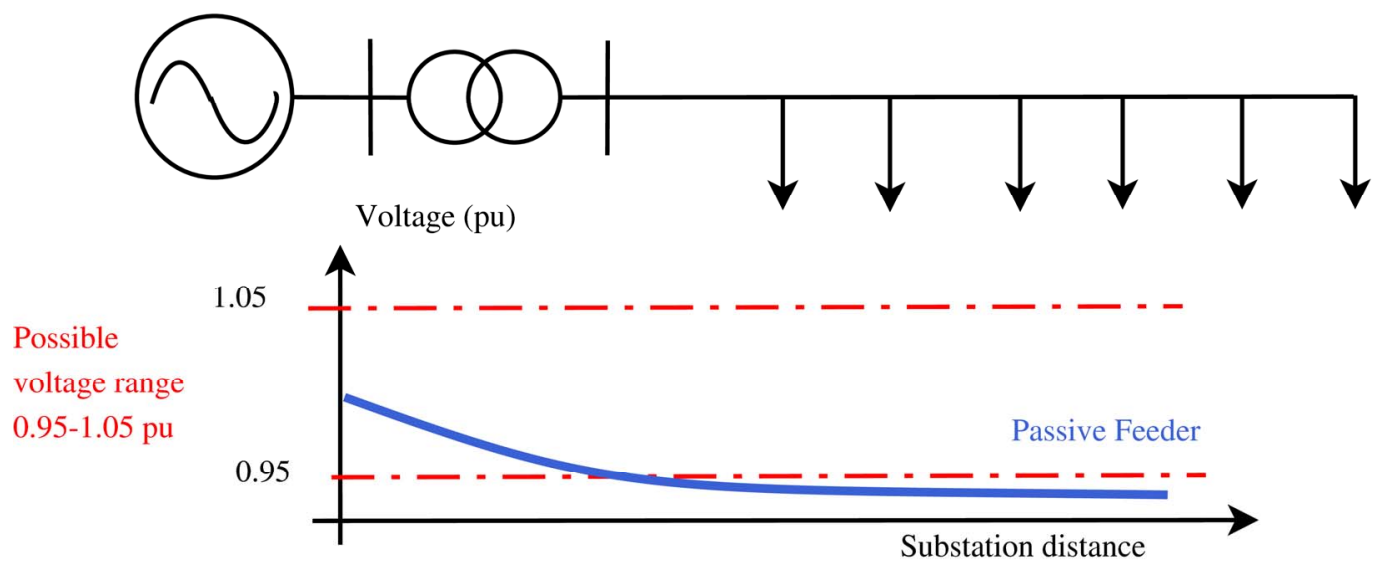

Figure 2. Voltage profile in a passive feeder. 


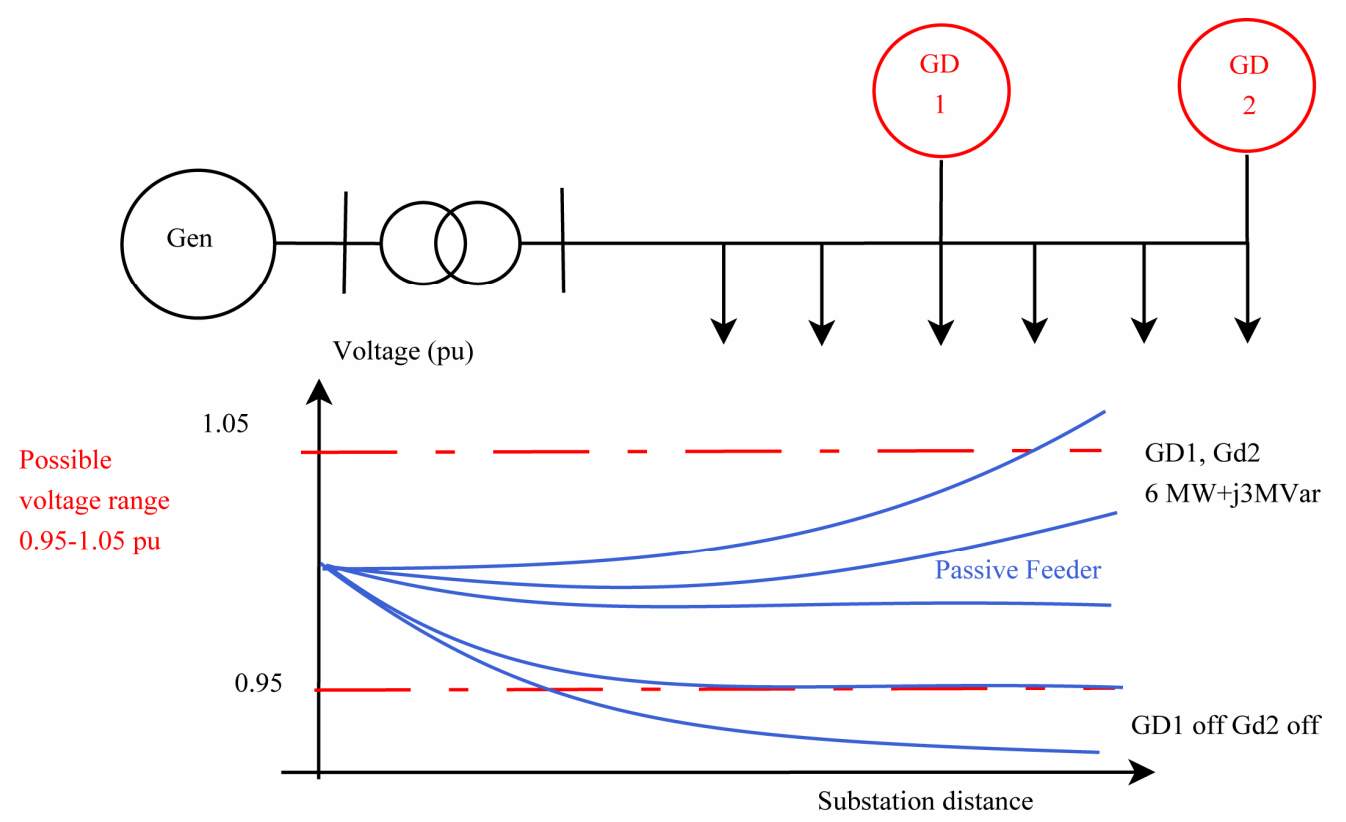

Figure 3. Different voltage profiles in an active feeder.

maintaining interventions in safety conditions (electrical system out of voltage).

The control and management issues concern:

- The parallel connection of islanded system and electrical power system due to automatic opening and re-closing operation to eliminate transient and semipermanent faults;

- The ground arc extinction, with the consequence of unsuccessful of re-closing operation and the power quality (frequency and voltage variations $[9,10]$.

\section{Current Scenario and Future Evolution of Distribution Systems: The Smart Grids}

The classical scenario of electrical distribution systems, being passive termination of the whole electrical system, is characterized by radial topology, vertically integration with centralized generation, dispatch and control, unidirectional power flows, "connect and forget" logic for the loads, multi directional power flows in presence of DG.

The future scenario foresees an active system that guarantees connectivity through an increasing level of interaction with the consumers and meeting (at least in the future) the end users energy demands in terms of flexibility, economy and reliability, using, at the same time, the benefits of the energy market liberalization. So, it will be characterized by:

- Interconnected and meshed topology;

- Distributed logic;

- Full DG integration [11];

- Multi-directional power flows;

- Logic of integration of the loads taking large flexibility.
The major features concern:

- Larger reliability through the implementation of all the most advanced distribution automation functions (for example integrated Volt/VAR control, outage management, reconfiguration);

- Possibility to integrate the consumers and their behavior within the design and management of the network through the Demand Side Management (DSM) [12];

- Adoption of advanced communication technologies and automated controls, emergency and market demand response;

- Self-healing i.e. the possibility to detect, analyze and solve problems;

- Use of different technologies for energy generation and storage;

- Full usage of the opportunities offered by the electrical market.

To realize these goals, it is necessary to apply in electrical distribution systems an advanced distribution automation and specifically SCADA (Supervisory, Control and Data Acquisition) systems, developing and implementing:

- A monitoring of the electrical systems through sensors;

- A data transmission system (optical fibbers, PLC, GSM, WI-FI, etc.);

- A decision system and a network automation and remote control.

In this way it will be possible to realize the new electrical smart distribution grids. A smart grid is, in fact, an electrical system able to smartly integrate activities of all 
connected users-energy producers, consumers, prosumers - with the aim of distributing energy in an efficient, sustainable, reliable and economical favorable way [7].

The most important goal of the smart grids is to transform the functionality of the present electricity transmission and distribution grids so to provide a more useroriented service, enabling the achievement of the 20/ 20/20 targets and guaranteeing, in a competitive market environment, high security, power quality and economic efficiency of electricity supplying. But how and in which way the transition from actual scenario to the new one will proceed? It is hard question to answer.

At this moment it is possible to imagine for the new grids three different models, that would be, also, considered as integrated parts of smart grids, active grids, micro grids and virtual utilities $[8,13]$.

\subsection{Active Grids}

An active grid is a network that does not only play the passive role of supplying the final consumers, but also in which the operator controls and/or rules the power required or generated by the loads or the generators, the bus voltages and the branch power flows. It is possible to assume an evolution in three different levels:

First-level: a simple local control of the generation at the connection point;

Second-level: a complete control system for all the distributed energy resources in the controlled area, realizing a coordinated dispatching and a voltage profile optimization (see Figure 4);

Third-level: creation of a strongly interconnected structure with a subdivision in cells ("local areas") responsible of their own management (protection, voltage regulation, etc.) that take part to the market, selling or buying energy to/from adjacent cells or from/to the transmission system (see Figure 5).

\subsection{Micro Grids}

A micro grid is a set of generators, loads and storage systems connected and able to operate independently from the electrical grid and that internally recreates the energy production and distribution system. In Figure 6 is reported an example of a micro grid presenting a micro grid separation device to performa the islanding operation, an energy manager connected to several power flow controllers and protection coordinators to control and manage the energy flowing in the micro grid branches and many different type sources to inlet energy not only from the main grid, but also to allow distributed generation.

It can be considered similar to the active network cell, since it is provided with a local control system that rules the exchanges of energy among the loads, generators and external network; moreover it can stay in intentional islanding configuration, disabling the loads that accept to be part of a "load curtailment” program [1].

\subsection{Virtual Utilities}

A virtual utility or virtual power plant realizes an optimized management and control of a set of distributed energy resources, in which all distributed generators, loads, storage systems are coordinated taking electric market signals into account. In conclusions, in all the possible imagined scenarios, a very important role will be played by the final users. The key for the development of smart grids concerns the active demand, i.e. the possibility for consumers to actively participate as actors in

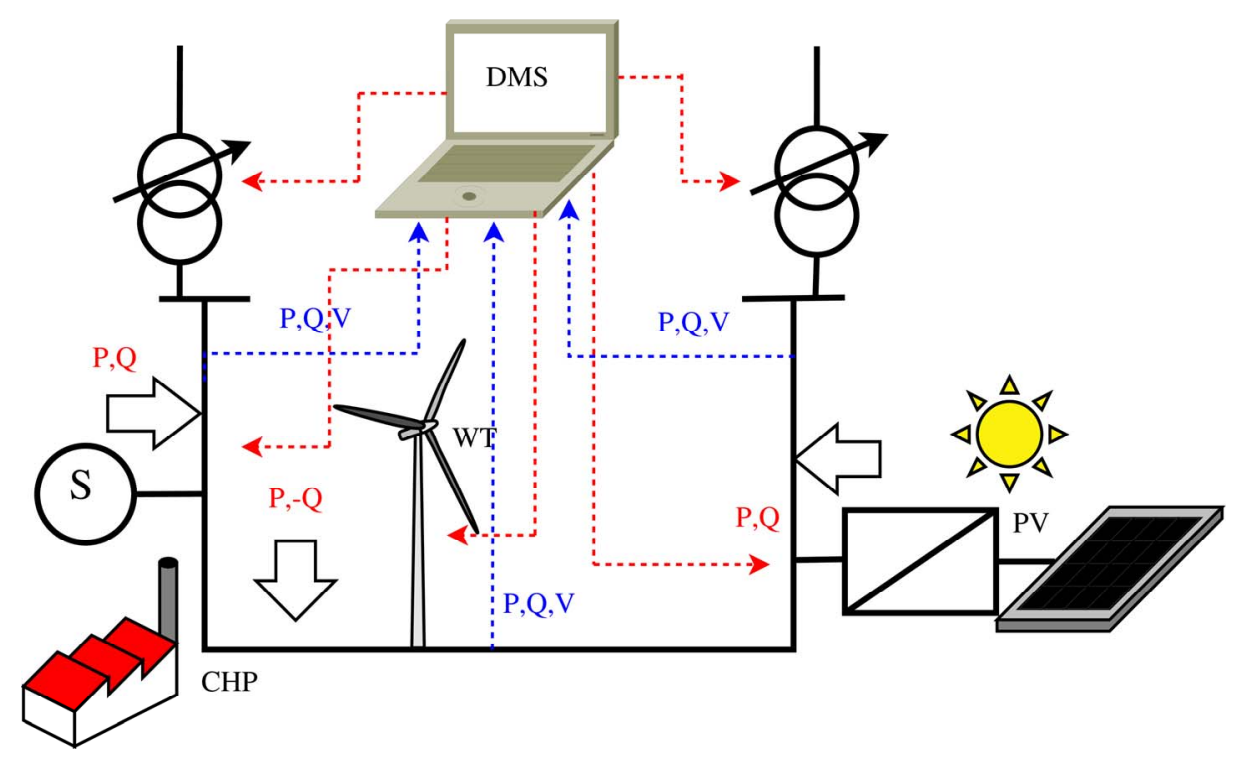

Figure 4. Decentralized control: coordinated dispatching and voltage profile optimization. 
the electrical system management and control.

\section{International Research Projects on Smart Grids}

Many international projects and research activities are focused on smart grids, underlining the importance of this issue. The European Smart Grids Technology Platform [7] represent the strategic deployment document for Europe's electricity networks of the future. The mission is to theorize and promote a common vision about the future (2020 and over) of electric grids.

The platform presents a road map organized in six high priority areas:

1) Optimization of grids management: improvement of the cooperation between Transmission System Operators (TSO), Distribution System Operators (DSO), TSO and DSO, improvement of the grids monitoring and control;

2) Optimization of grids infrastructure: new infrastructures realization, mainly of transmission type, present infrastructures optimization, superconductor technologies development;

3) Large-scale integration of intermittent generation: development of grids to transport the energy generated by wind and photovoltaic plants, development of energy storage systems;

4) Information communication technology: development of easy, strong, safe and flexible communication infrastructures, Standardization of data types and transmission protocols;

5) Active distribution grids: spread the transmission grids services (power flow management, balance, contingencies analysis) to the distribution systems, grid topologies optimization, implementation of smart systems to the grid, communication infrastructures development;
6) New markets, users, energetic efficiency: development of new market models for the active demand integration, spread of bidirectional interface devices between users and market, knowledge boost towards the energy savings and the energetic efficiency improvement.

As known the EU Energy and climate package, that is the new European energetic strategy aiming at guaranteeing a sustainable development, electric market efficiency and quality and security of energy supply, previews some goals that must be gained in two steps: 2020 and 2050 .

The first step concerns the 20-20-20 goals: reduction of $20 \%$ of greenhouse gases respect to 2005, adopted as reference year because of the start of European Emission trading (EU ETS);

$20 \%$ of final consumptions of electrical energy produced by means renewables;

$20 \%$ reduction of energy consumption. In 2008, to

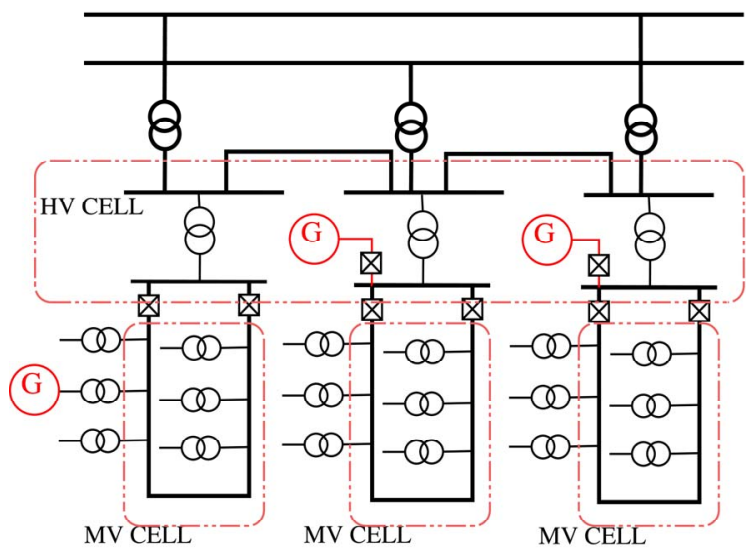

Figure 5. Distribution system organized by cells (local areas).

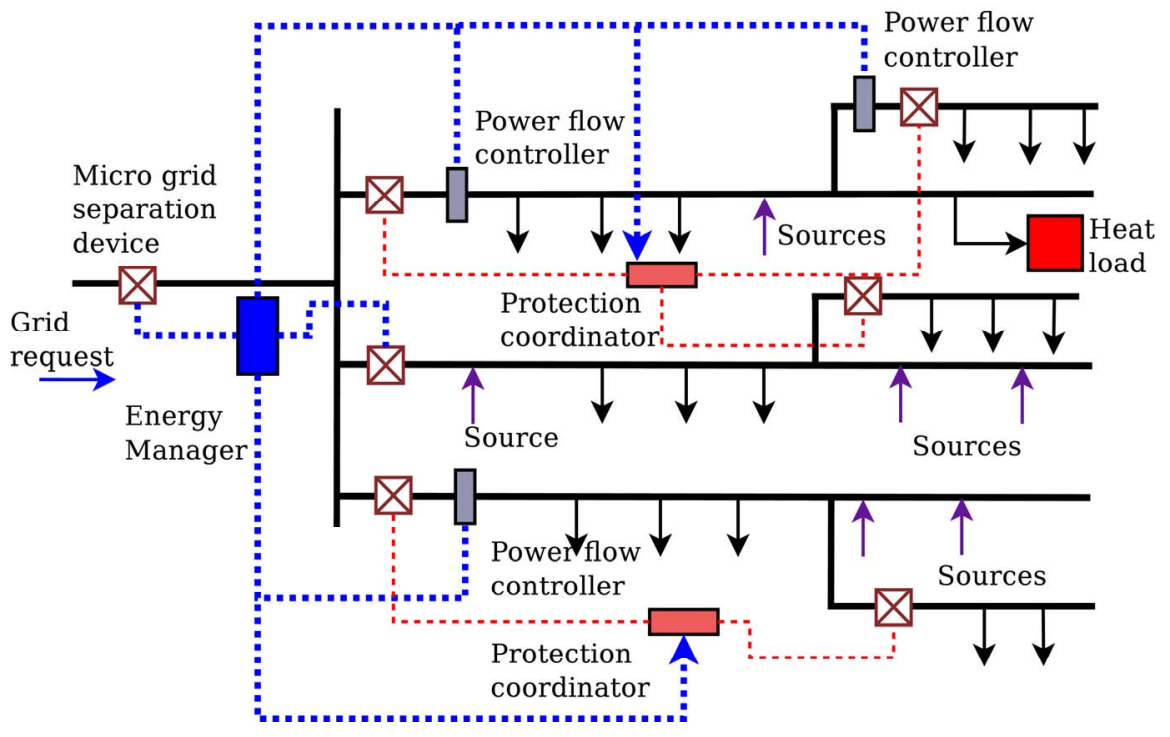

Figure 6. Example of a micro grid. 
achieve these goals the European Council and Parliament have adopted the SET Plan-Strategic Energy Technology Plan, as planning and coordination document.

The SET Plan proposes six European Industrial Initiatives (EII), among which the smart grid. In fact, in June 2010, during the SET Plan Conference in Madrid, the European Electricity Grids Initiative (EEGI) has been presented, with a precise research and development program. The EEGI [14] is proposed by 7 Transmission System Operators (TSO) (Amprion, Elia, Red Electrica de Espana, RTE, Tennet, Transpower, 50 Hertz) and 7 Distribution System Operators (DSO) (CEZ, EON, Enel, Erdf, Iberdrola, RWE, Vattenfall). Key partners are the European Network of Transmission Systems Operators for Electricity (ENTSO-E) and the European Distribution Systems Operators Association for Smart Grids (EDSOSG). The initiative, characterized by a time duration of 8 years (2010-2018) and by a cost of 2 billions Euro, proposes a program of research, development and demonstration (RD\&D) aiming at creating a new flexible, economic, efficient, sustainable, smart electrical system.

In particular, the major features are:

- Development and integration of innovative technologies for power systems and their validation in real conditions;

- Development of suitable solutions for other energetic initiatives (solar, wind) to increase renewables and distributed energy resources (DER);

- Creation of a strictly synergy among electrical systems operators, equipment and ICT manufacturers.

In particular the EEGI vision involves electrical energy producers, end-consumers and prosumers.

One of the most important item concerns the integration of new generation and consumption models with the particular goal of creating the smart consumer, by means of: the integration, in the control and management of the electrical systems, of the active demand; the development of the energetic efficiency of end-consumers and the development of new business opportunities for electric market actors, overall for end-users.

Concerning the smart consumer, the EEGI RD\&D program proposes a specific cluster named "integration of smart customers", with two projects: Active Demand Response and Energy Efficiency from integration with Smart Homes. In 2008 to support and contribute in a coordinated way to the SET PLAN goals, 14 European research institutes have created the European Energy Research Alliance (EERA). Among all the joint research program proposed by EERA, the Smart Grids one, already started, foresees 4 sub-programs (SP), each subdivided in many research activities:

- SP 1-Network Operation: Adaptation of primary control cycle and automation, network monitoring system and ICT, ancillary services, fault and outage man- agement, distributed generation management, load management;

- SP 2-Energy Management: Simulation and Analysis Model, System Operation with DER and ICT, Market Design with DER, System Design with DER;

- SP 3-Control System Interoperability: State of the art and terminology, Classification of Control Systems, Use Cases, Technical Communication Requirements, Standards and Protocols, Cyber Security;

- SP 4-Electric Energy Storage (EES) Technologies, Performance Testing of Technologies, Integration of Storage Resources to Smart Grids possible Services, Control Algorithms for Storage, Applications in Smart Grids, Economic and Technical Benefits of incorporating an EES onto Network.

In the area of smart distribution grids, a very important European research project, financially supported by the 7th Framework Program, is working: ADDRESS (Active Distribution network with full integration of Demand and distributed energy RESourceS). ADDRESS is a large scale R\&D project, involving 25 partners (distributors, networks, ICT and trade operators, research institutes, industries) from 11 European countries, with a cost of 15.7 M (9 M funded). The vision concerns:

1) Flexibility-active demand and power flow optimization both at local and global level;

2) Reliability-technologies development for distributed control, safety and efficient management;

3) Accessibility-commercial and standard barriers removal, fully DG integration, RES, active demand;

4) Economy and Savings-energy consumption and sustainable development, bills amounts reduction.

Particularly interesting is the Italian project "Smart Distribution Network Operation" (SDNO) and developed by ENEL-Distribuzione, the most important Italian distribution operator. The finality of the SDNO project regards:

1) The evaluation of the generators and electrical system features to enable high penetration of DG, the definition and realization of new interface components and new network systems both hardware and software;

2) The testing of apparatus and systems in laboratories and in real electrical systems;

3) The promotion new national and international rules for connection criteria and electrical system control.

In more details, the project foresees the development or realization and testing of new functional requirements for automatic control protection systems, new Supervisory Control and Data Acquisition (SCADA) at HV/MV substation for MV system automatic control, DG dispatching and load control (DSM-demand side management). Another important aspect considered in the project is issued to new remote terminal units (RTU) in MV/LV substation for control and automation; new RTU 
for DG and load control (DSM); innovative rules for voltage regulation based on HV/MV transformers control and on DG dispatching.

\section{Conclusions}

All the hypothetical scenarios related to smart grids need evolution and development processes involving many aspects, which are today very interesting areas for studying and researching; in fact, the new challenges, that have to be faced, concern:

- Technical aspects: new criteria for electrical systems planning, design, control and management;

- Technological aspects: evolution of components, apparatus and systems (both hardware and software);

- Economical and policy-regulatory aspects: free markets, roles and responsibilities of all actors involved, connection rules, load shedding, generation curtailment, etc.;

- Social aspects: energy policies really sustainable, environmental impact reduction, energetic resources supplying diversification, to advantage renewable development, increase of power and services quality, lower costs for users (real competition).

A real cultural revolution has started, but, as already said by Albert Einstein,

"We can't solve problems by using the same kind of thinking we used when we created them".

\section{Acknowledgements}

This work was supported by MIUR (Italian Ministry of University and Research), by the "Sustainable Development and Energy Saving Laboratory" (SDESLAB) part of the UNINETLAB of the University of Palermo and financially supported by the project BeyWatch IST223888 funded by the European Community, web page: http://www.beywatch.eu/

\section{REFERENCES}

[1] C. Cecati, F. Genduso, R. Miceli and G. R. Galluzzo, “A Suitable Control Technique for Fault-Tolerant Converters in Distributed Generation,” IEEE International Symposium on Industrial Electronics (ISIE), L'Aquila 27-30 June 2011, pp. 107-112.

[2] K. Knauss, C. Warren and D. Kearns, "An Innovative Approach to Smart Automation Testing at National Grid," Transmission and Distribution Conference and Exposition (T\&D), 7-10 May 2012, pp. 1-8.

[3] P. Chiradeja, "Benefit of Distributed Generation: A Line
Loss Reduction Analysis,” Transmission and Distribution Conference and Exhibition, Asia and Pacific, Bangkok, 2005, pp. 1-5.

[4] D. L. Jia, X. L. Meng and X. H. Song, "Study on Technology System of Self-Healing Control in Smart Distribution Grid,” 2011 International Conference on Advanced Power System Automation and Protection, Beijing, 16-20 October 2011, pp. 26-30. doi:10.1109/APAP.2011.6180379

[5] A. O. Di Tommaso, S. Favuzza, F. Genduso and R. Miceli, "Development of Diagnostic Systems for the Fault Tolerant Operation of Micro-Grids," International Symposium on Power Electronics, Electrical Drives, Automation and Motion, Palermo, 14-16 June 2010, pp. 1645-1650.

[6] F. Genduso, R. MIceli and G. R. Galluzzo, "Flexible Power Converters for the Fault Tolerant Operation of MicroGrids,” XIX International Conference on Electrical Machines (ICEM), Palermo, 6-8 September 2010, pp. 1-6.

[7] C. Eu, "European Smartgrids Technology Platform-Vision and Strategy for Europe Electricity Networks of the Future,” European Commission, 6-8 September 2006.

[8] M. Samotyj and B. Howe, “Creating Tomorrow’s Intelligent Electric Power Delivery System,” 18th International Conference and Exhibition on Electricity Distribution, Palo Alto, 6-9 June 2005, pp. 1-5.

[9] K. Jennett, C. Booth and M. Lee, "Analysis of the Sympathetic Tripping Problem for Networks with High Penetrations of Distributed Generation,” International Conference on Advanced Power System Automation and Protection (APAP), Glasgow, 16-20 October 2011, pp. $384-$ 389. doi:10.1109/APAP.2011.6180432

[10] M. Hagh, N. Ghadimi, F. Hashemi and S. Zerbadst, "New Islanding Detection Algorithm for Wind Turbine,” 10th International Conference on Environment and Electrical Engineering (EEEIC), Ahar, 8-11 May 2011, pp. 1-5.

[11] A. O. Di Tommaso, F. Genduso, G. R. Galluzzo and R. Miceli, "Computer Aided Optimization via Simulation Tools of Energy Generation Systems with Universal Small Wind Turbines," 3rd IEEE International Symposium on Power Electronics for Distributed Generation Systems (PEDG), 25-28 June 2012, pp. 570-577. doi:10.1109/PEDG.2012.6254059

[12] F. Aalamifar, H. Hassanein and G. Takahara, "Viability of Powerline Communication for the Smart Grid,” 26th Biennial Symposium on Communications (QBSC), Kingston, 28-29 May 2012, pp. 19-23. doi:10.1109/QBSC.2012.6221343

[13] M. Loddo, “Pianificazione e Gestione Delle Reti Attive," Ph.D. Thesis, University of Cagliari, Cagliari, 2008.

[14] ENTSO-E, “Roadmap 2010-2018 and Detailed Implementation Plan 2010-12,” European Commission, The European Electricity Grid Initiative (EEGI), 2010. 